\title{
Impact of preoperative pulmonary function on outcomes after open repair of descending and thoracoabdominal aortic aneurysms
}

\author{
Leonard N. Girardi, MD, Christopher Lau, MD, Monica Munjal, MS, Mohamed Elsayed, MD, \\ Ivancarmine Gambardella, MD, Lucas B. Ohmes, MD, and Mario Gaudino, MD
}

\begin{abstract}
Objective: To evaluate the impact of preoperative pulmonary function on outcomes after open repair of descending thoracic (DTA) and thoracoabdominal aortic (TAAA) aneurysms.

Methods: The outcomes of patients undergoing open repair of DTA or TAAA were analyzed in relation to the results of preoperative pulmonary function tests. Receiver operating characteristic was adopted to assess the effect of forced expiratory volume in one second (FEV1) on the incidence of mortality. Logistic regression analysis and propensity score matching were used.
\end{abstract}

Results: Between 1997 and 2015, 726 patients underwent open DTA or TAAA repair. Pulmonary function tests were available in 711 (97.9\%). Receiver operating characteristic analysis revealed the cutoff value of FEV1 to be $50 \%$. Propensity score matching led to 149 pairs of patients with FEV1 below and above $50 \%$ with only limited residual imbalance. In the matched population operative mortality was $11.4 \%$ and $6.0 \%$ in patients with FEV1 $\leq 50 \%$ and FEV $1 \geq 51 \%$, respectively $(P=.10)$. The incidence of major adverse events was $33.1 \%$ in cases with FEV1 $\leq 50 \%$ and $19.5 \%$ in those with FEV $1 \geq 51 \%$ $(P=.008) . \mathrm{FEV} 1 \leq 50 \%$ was associated with a $6.99 \times$ increase in the risk of major postoperative adverse events at logistic regression analysis.

Conclusions: Preoperative FEV $1<50 \%$ is strongly predictive of increased respiratory failure, tracheostomy, and operative mortality in patients undergoing open DTA/TAAA repair. For these very high-risk patients with either extensive TAAAs or anatomy unsuitable for endovascular repair, medical therapy may offer the best long-term survival. (J Thorac Cardiovasc Surg 2017;153:S22-9)

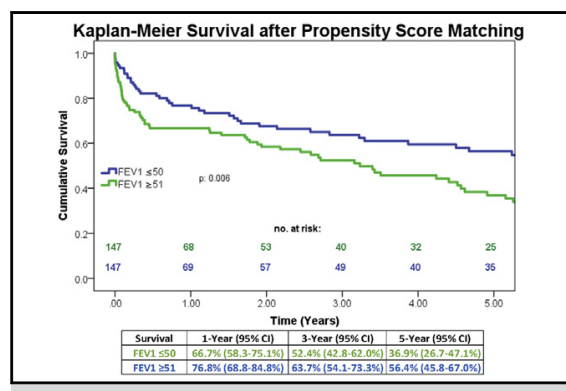

Long-term survival of matched patients according to preoperative pulmonary function.

\section{Central Message}

Patients with a forced expiratory volume in 1 second $<50 \%$ are at high-risk for respiratory failure, tracheostomy, and operative mortality after open descending thoracic aneurysm/ thoracoabdominal aortic aneurysm repair.

\section{Perspective}

Patients in need of open descending thoracic aneurysm/thoracoabdominal aortic aneurysm repair with extremely reduced pulmonary function and additional comorbidities may be better served with a conservative nonintervention strategy. Patients with an forced expiratory volume in 1 second $<50 \%$ are at high risk for respiratory failure, tracheostomy, and operative mortality after open descending thoracic aneurysm/thoracoabdominal aortic aneurysm repair.

See Editorial Commentary page S30.
Open repair of descending thoracic (DTA) and thoracoabdominal aortic aneurysms (TAAAs) remains a formidable

From the Department of Cardiothoracic Surgery, Weill Cornell Medicine, New York, NY.

Read at the 2016 Annual Aortic Symposium of the American Association of Thoracic Surgeons, New York, New York, May 12-13, 2016.

Received for publication June 20, 2016; revisions received Oct 17, 2016; accepted for publication Oct 31, 2016; available ahead of print Dec 2, 2016.

Address for reprints: Leonard N. Girardi, MD, Department of Cardiothoracic Surgery, Weill Cornell Medicine, 525 E 68th St, M 404, New York, NY 10065 (E-mail: lngirard@med.cornell.edu).

0022-5223/\$36.00

Copyright (c) 2016 by The American Association for Thoracic Surgery

http://dx.doi.org/10.1016/j.jtcvs.2016.10.055 undertaking, with results that can be influenced dramatically by surgical experience and the use of advanced organpreservation techniques. ${ }^{1,2}$ Outcomes have improved dramatically during the last 2 decades $^{3}$ and patients requiring these high-risk procedures, even in the setting of rupture,

Scanning this QR code will take you to the supplemental figures, tables, and video for this article. 


\section{Abbreviations and Acronyms \\ COPD $=$ chronic obstructive pulmonary disease \\ $\mathrm{CPB}=$ cardiopulmonary bypass \\ DTA = descending thoracic aneurysm \\ FEV1 = forced expiratory volume in 1 second \\ MAE = major adverse event \\ OR = odds ratio \\ PSM = propensity score matching \\ TAAA $=$ thoracoabdominal aortic aneurysm \\ TEVAR $=$ thoracic endovascular aneurysm repair}

infection, or acute dissection, are experiencing less operative mortality with a significant reduction in major postoperative complications. . $^{4-6}$

It is not surprising that proper patient evaluation and preparation before highly complex surgery can contribute mightily to improvements in surgical outcomes. ${ }^{7-10}$ In particular, with the growing age and overall increase in the prevalence of chronic obstructive pulmonary disease (COPD) in the population, ${ }^{11}$ insight into and management of a patient's pulmonary status has taken on greater importance in all facets of cardiovascular and thoracic surgery. ${ }^{7,8,12-14}$ Upwards of $25 \%$ of a large, contemporary group of patients undergoing open DTA or TAAA repair have advanced COPD. ${ }^{15}$ And although a greater percentage of patients requiring thoracic aneurysm repair are being treated with endovascular repair (thoracic endovascular aneurysm repair; TEVAR), ${ }^{16}$ there are a substantial number of patients that will require open repair because of anatomy, age, or the underlying etiology of the disease. In addition, short- and long-term complications from TEVAR continue to increase, and a majority of these patients will require open repair to treat their aneurysmal disease. ${ }^{17}$

The negative influence of pulmonary disease on outcome after TAAA repair was explored in a previous $\mathrm{era}^{18}$; however, with advancements in surgical technique and postoperative critical care, patients previously considered poor candidates for surgery, or those for whom endovascular repair is considered imprudent, are now considered operable. In an effort to better risk-stratify patients with COPD presenting for aneurysm repair, we examined a contemporary cohort of high-risk patients undergoing open repair in a high-volume aortic center. We used propensity matching and logistic regression analysis to eliminate confounding variables to better define the association between preoperative pulmonary function and overall outcomes after open thoracic aneurysm repair.

\section{PATIENTS AND METHODS \\ Patient Population and End Points}

This study was approved by the institutional review board. The need for individual patient consent was waived. A review of prospectively collected data from the Weill Cornell Medicine Department of Cardiothoracic Surgery - Aortic database was conducted to identify all patients who underwent repair of TAAA or DTA from May 1997 to October 2015.

Primary end points were operative mortality and follow-up death from any cause. Secondary end points were the incidence of major postoperative complications (myocardial infarction, stroke, new-onset renal insufficiency requiring dialysis, need for tracheostomy, spinal cord complications) and a composite of postoperative major adverse events (MAEs: operative death and the previously listed major postoperative complications).

All patients referred for repair undergo preoperative pulmonary function testing. An arterial blood gas is drawn on room air to assess baseline partial pressure of oxygen partial pressure of carbon dioxide. Patients with a forced expiratory volume in 1 second (FEV1) $<50 \%$, a diffusion capacity (diffusing capacity of the lungs for carbon monoxide) less than $40 \%$, or with a partial pressure of carbon dioxide greater than 50 are considered high risk for postoperative pulmonary complications and are referred to a pulmonologist for evaluation, treatment, and physiotherapy before surgery. If the high-risk patients are in need of urgent/emergent aneurysm repair, alternative endovascular options are explored and, if unavailable, the patient and family are counseled on the greater potential for prolonged intubation and/or the need for tracheostomy. The Crawford classification was used to define the extent of TAAA. Preoperative renal insufficiency was defined as a creatinine level $\geq 1.5 \mathrm{mg} / \mathrm{dL} .{ }^{19}$

\section{Surgical Technique}

After intubation with a single lumen endotracheal tube, insertion of a spinal drain, placement of volume lines, and hemodynamic monitoring, a bronchial blocker is placed into the left main stem bronchus. Once in a modified right lateral decubitus position, positioning of the blocker is confirmed with bronchoscopy and the balloon is inflated to begin left lung deflation. This allows for an assessment of how well the patient will tolerate single-lung ventilation during surgery. If significant hypoxemia occurs, positive end-expiratory pressure, inverse ratio ventilation, and bronchodilators are used. Left lung insufflation may be necessary to return oxygen saturation greater than $90 \%$ before aortic cross-clamping. Double-lumen endotracheal tubes rarely are used in an effort to eliminate the need to insert a single-lumen tube and avoid risk of airway loss after surgery when laryngeal, upper airway, and facial edema is significant.

Details of the surgical technique have been published. ${ }^{6}$ In summary, a fifth or sixth intercostal space thoracotomy or thoracoabdominal incision was used in all patients. Resection of adjacent ribs was performed when necessary. In patients with impaired pulmonary function, the clamp-andsew technique was our primary strategy, particularly in case of free rupture or isolated descending aortic pathology. In extent I, III, and IV TAAAs, the clamp-and-sew strategy was used and cold renal perfusion or blood visceral perfusion were added if the visceral and renal vessels were involved. For contained ruptured, extent II aneurysms requiring extensive reconstruction and acute type B dissections, left heart bypass was adopted. Finally, when proximal aortic control was unattainable, cardiopulmonary bypass (CPB) and deep hypothermic circulatory arrest were used. Reinfusion of shed blood was performed with a Belmont warm rapid infusion system (Belmont Instrument Corporation, Billerica, Mass). Core temperature was allowed to decrease to $33^{\circ} \mathrm{C}$ before crossclamping the aorta. Reimplantation of intercostal arteries was performed with the inlay-inclusion technique. Visceral and renal arteries were either reimplanted or bypassed as dictated by the anatomy. Hemashield Dacron grafts (Macquet Corporation, Oakland, NJ) were used. Preoperative spinal drain insertion was attempted in all hemodynamically stable patients. In unstable patients, spinal drain insertion was performed after surgery before transporting the patient to the intensive care unit. Drains were maintained with an intrathecal pressure less than $12 \mathrm{~cm} \mathrm{H}_{2} \mathrm{O}$ for 72 hours, and mean arterial pressure was maintained at greater than $85 \mathrm{~mm} \mathrm{Hg}$ (see Video 1). 


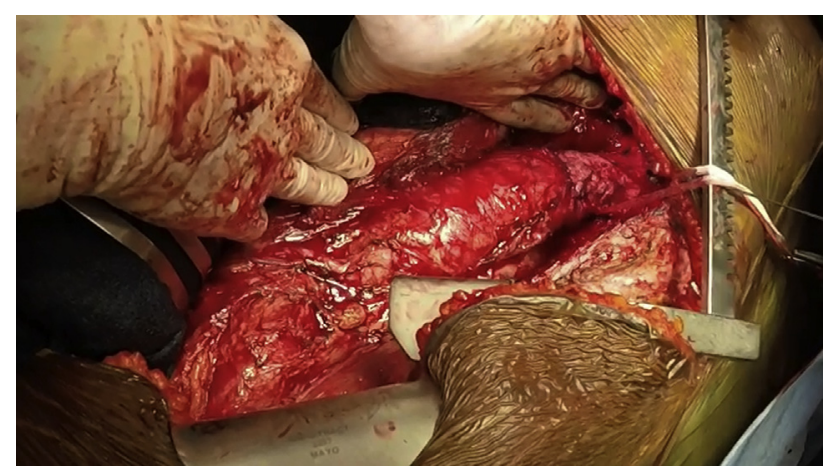

VIDEO 1. Open repair of thoracoabdominal aortic aneurysm. Video available at: http://www.jtcvsonline.org/article/S0022-5223(16)31448-9/addons.

\section{Statistical Analysis}

For baseline characteristics, variables are summarized as mean for continuous variables and percentage for categorical variables. Data from the study population were compared with $\chi^{2}$ for categorical variables and Student $t$ test for continuous variables.

The receiver operating characteristic curve was used to assess the effect of FEV1 on operative mortality, and a cut-off value was extracted.
Univariate and multivariate analysis for MAEs was computed for demographic and preoperative predictors of such events. Backward stepwise multivariate logistic regression analysis was performed to identify specific preoperative predictors. Predictors chosen for analysis were those found to be significant at univariate analysis.

Because of the number of variables differing between the 2 groups relative to the number of events, however, we decided to use propensity score matching (PSM) ${ }^{20}$ PSM was performed according to a described method. ${ }^{21}$ Variables chosen for the PSM were those relevant in the comparison of differing FEV1 levels. Selected variables for PSM were age, preoperative renal status, procedure status (elective vs urgent/emergent), ejection fraction, extent, and type of the aneurysm.

Postoperative survival was assessed with the Kaplan-Meier method. Groups were compared by the use of log-rank analysis. Cox proportional hazard analysis was performed to determine significant risk factors of long-term survival in the matched dataset. Univariate predictors with probability less than 0.20 were included in the Cox regression model.

\section{RESULTS \\ Patient Profiles}

During the study period, 726 patients underwent open DTA/TAAA repair; $711(97.9 \%)$ had preoperative

TABLE 1. Preoperative patient characteristics

\begin{tabular}{|c|c|c|c|c|}
\hline \multirow[b]{2}{*}{ Variable } & \multicolumn{4}{|c|}{ Subgroups } \\
\hline & Entire cohort $(n=711)$ & FEV1 $\leq 50(n=159)$ & $\operatorname{FEV1} \geq 51(\mathrm{n}=\mathbf{5 5 2})$ & $P$ value \\
\hline Males & $414(58.2)$ & $72(45.3)$ & $342(62.0)$ & $<.001$ \\
\hline Age (mean, SD) & $64.8 \pm 14.4$ & $71.4 \pm 9.8$ & $62.8 \pm 15.0$ & $<.001$ \\
\hline Smoking & $543(76.4)$ & $153(96.2)$ & $390(70.7)$ & $<.001$ \\
\hline Hypertension & $685(96.3)$ & $157(98.7)$ & $528(95.7)$ & .067 \\
\hline Chronic pulmonary disease & $290(40.8)$ & $147(93.0)$ & $143(25.9)$ & $<.001$ \\
\hline Previous heart surgery & 348 (48.9) & $70(44.0)$ & $278(50.3)$ & .159 \\
\hline Peripheral vascular disease & $192(27.0)$ & $71(44.7)$ & $121(21.9)$ & $<.001$ \\
\hline Diabetes & $64(9.0)$ & $22(13.9)$ & $42(7.6)$ & .015 \\
\hline \multicolumn{5}{|l|}{ Renal status } \\
\hline Renal failure & $178(25.0)$ & $76(47.8)$ & $102(18.5)$ & $<.001$ \\
\hline Hemodialysis & $21(3.0)$ & $7(4.4)$ & $14(2.5)$ & \\
\hline Previous stroke & $42(5.9)$ & $15(9.4)$ & $27(4.9)$ & .032 \\
\hline Connective tissue disorders & $78(11.0)$ & $4(2.5)$ & $74(13.4)$ & $<.001$ \\
\hline \multicolumn{5}{|l|}{ Etiology } \\
\hline Chronic dissection & $240(33.8)$ & $32(20.1)$ & $208(37.6)$ & $<.001$ \\
\hline Atherosclerosis & $362(50.9)$ & $100(62.9)$ & $262(47.5)$ & \\
\hline Acute dissection & $55(7.7)$ & $19(11.9)$ & $36(6.5)$ & \\
\hline Other & $54(7.6)$ & $8(5.0)$ & $46(8.3)$ & \\
\hline TAAA & $486(68.4)$ & $115(72.3)$ & $371(67.2)$ & .222 \\
\hline \multicolumn{5}{|l|}{ Aneurysm extent (TAAA only) } \\
\hline I & $246(50.6)$ & $56(48.7)$ & $190(51.2)$ & .545 \\
\hline II & $98(20.2)$ & $27(23.5)$ & $71(19.1)$ & \\
\hline III & 105 (21.6) & $26(22.6)$ & $79(21.3)$ & \\
\hline IV & $37(7.6)$ & $6(5.2)$ & $31(8.4)$ & \\
\hline \multicolumn{5}{|l|}{ Procedure status } \\
\hline Elective & $340(47.8)$ & $45(28.3)$ & $295(53.4)$ & $<.001$ \\
\hline Urgent/emergent & $371(52.2)$ & $114(71.7)$ & $257(46.6)$ & \\
\hline Preoperative paraparesis/paraplegia & $10(1.4)$ & $7(4.4)$ & $3(0.5)$ & .001 \\
\hline Aneurysm size (mean, SD) & $6.8 \pm 1.5$ & $7.3 \pm 1.5$ & $6.8 \pm 1.5$ & $<.001$ \\
\hline Ejection fraction (mean, SD) & $48.9 \pm 8.1$ & $46.6 \pm 8.7$ & $49.6 \pm 7.9$ & $<.001$ \\
\hline FEV1 (mean, SD) & $64.2 \pm 13.1$ & $46.5 \pm 7.3$ & $69.3 \pm 9.4$ & $<.001$ \\
\hline
\end{tabular}

Data presented as $\mathrm{n}(\%)$, unless otherwise noted; 15 patients without preoperative pulmonary function tests were excluded. FEVI, Forced expiratory volume in 1 second; $S D$, standard deviation; TAAA, thoracoabdominal aortic aneurysm. 
pulmonary function tests available and constitute the basis of this report. Because of an inability to confirm whether preoperative arterial blood gas analysis was obtained without supplemental oxygen, those results could not be analyzed in detail. The preoperative comorbid conditions of the patients are summarized in Table 1 .

Receiver operating characteristic analysis revealed an area under the curve of 0.726 when modeling FEV1 status as a predictor of operative mortality, with a sensitivity of 0.500 and specificity of 0.207 for the FEV1 cut-off value of $50 \%$ (Figure E1).

FEV $1 \leq 50 \%$ was present in $159(21.9 \%)$ of patients. These patients were significantly older, with larger aneurysms, more urgent/emergent cases, and had a greater preponderance of comorbid conditions, including peripheral vascular disease, diabetes, previous stroke, and worse renal function. The FEV1 $\leq 50 \%$ group had far fewer dissections and patients with connective tissue

TABLE 2. Preoperative patient characteristics after propensity score matching

\begin{tabular}{|c|c|c|c|}
\hline \multirow[b]{2}{*}{ Variable } & \multicolumn{3}{|c|}{ Subgroups } \\
\hline & $\begin{array}{c}\text { FEV1 } \leq 50 \\
(\mathrm{n}=149)\end{array}$ & $\begin{array}{c}\text { FEV1 } \geq 51 \\
(\mathrm{n}=149)\end{array}$ & $\begin{array}{c}P \\
\text { value }\end{array}$ \\
\hline Males & $64(43.0)$ & $67(45.0)$ & .726 \\
\hline Age (mean, SD) & $71.1 \pm 10.0$ & $71.3 \pm 10.1$ & .858 \\
\hline Smoking & $143(96.0)$ & $131(87.9)$ & .011 \\
\hline Hypertension & $148(99.3)$ & $148(99.3)$ & NS \\
\hline Chronic pulmonary disease & $138(92.6)$ & $62(41.6)$ & $<.001$ \\
\hline Previous heart surgery & $63(42.3)$ & $64(43.0)$ & .907 \\
\hline Diabetes & $21(14.2)$ & $15(10.1)$ & .276 \\
\hline \multicolumn{4}{|l|}{ Renal status } \\
\hline Renal failure & $66(44.3)$ & $62(41.6)$ & .073 \\
\hline Hemodialysis & $7(4.7)$ & $1(0.7)$ & \\
\hline Previous stroke & $19(12.8)$ & $14(9.4)$ & .345 \\
\hline Connective tissue disorders & $3(2.0)$ & $7(4.7)$ & .358 \\
\hline \multicolumn{4}{|l|}{ Etiology } \\
\hline Chronic dissection & $30(20.2)$ & $41(27.6)$ & .396 \\
\hline Atherosclerosis & $92(61.7)$ & $87(58.4)$ & \\
\hline Acute dissection & $19(12.8)$ & $13(8.7)$ & \\
\hline Other & $8(5.4)$ & $8(5.4)$ & \\
\hline TAAA & $107(71.8)$ & $113(75.8)$ & .429 \\
\hline \multicolumn{4}{|l|}{ Aneurysm extent (TAAA only) } \\
\hline I & $51(47.7)$ & $55(48.7)$ & .965 \\
\hline II & $24(22.4)$ & $24(21.2)$ & \\
\hline III & $26(24.3)$ & $26(23.0)$ & \\
\hline IV & $6(5.6)$ & $8(7.1)$ & \\
\hline \multicolumn{4}{|l|}{ Procedure status } \\
\hline Elective & $45(30.2)$ & $46(30.9)$ & .900 \\
\hline Urgent/emergent & $104(69.8)$ & $103(69.1)$ & \\
\hline Aneurysm size (mean, SD) & $7.2 \pm 1.5$ & $7.4 \pm 1.6$ & .404 \\
\hline Ejection fraction (mean, SD) & $47.0 \pm 8.3$ & $47.0 \pm 8.6$ & .995 \\
\hline FEV1 (mean, SD) & $46.3 \pm 7.5$ & $66.4 \pm 10.0$ & $<.001$ \\
\hline
\end{tabular}

Data presented as n (\%), unless otherwise noted. FEVI, Forced expiratory volume in 1 second; $S D$, standard deviation; $N S$, not significant; TAAA, thoracoabdominal aortic aneurysm. disorders. When we examined these same parameters for the 149 matched patients, only smoking, COPD, and FEV1 remained significantly more common in the low FEV1 group (Table 2, Figure E2).

\section{Operative Data}

Details of the operative data for the overall cohort and unmatched patient populations are presented in Table E1. Spinal drainage was used in $84.1 \%$ of the total cohort. Clamp and sew was the primary reconstruction strategy $(462 / 711,65 \%)$, whereas circulatory arrest was rarely used $(61 / 711,8.6 \%)$. Intercostal reimplantation was performed in $40.4 \%$ (287/711) of cases and renal/visceral perfusion was deemed necessary in 21\% (150/711). Mean crossclamp time was $30.1 \pm 11.5$ minutes with the clamp-and-sew technique, whereas the mean time of left heart bypass was $27.9 \pm 10.5$ minutes in the partial bypass group. Mean time under circulatory arrest was $35.5 \pm 12.9$ minutes. Intraoperative data within the matched populations are outlined in Table 3.

\section{Postoperative Outcomes and Follow-up}

Details of outcome data for the overall and unmatched population are presented in Table E2. Overall operative mortality was $5.6 \%$ (40/711). The most frequent causes of death were multiple organ failure in 9, myocardial infarction in 5, respiratory failure in 5, and stroke in 4 . In an unmatched population, mortality was significantly more likely in those with an FEV1 $\leq 50 \%(12.6 \%$ vs $3.6 \% ; P<.001)$, as was the need for postoperative tracheostomy $(16.4 \%$ vs $4.9 \%, P<.001)$ and new need for dialysis $(11.3 \%$ vs $3.3 \%, P<.001)$. There was no

TABLE 3. Intraoperative data after propensity score matching

\begin{tabular}{lccr}
\hline & \multicolumn{3}{c}{ Subgroups } \\
\cline { 2 - 4 } \multicolumn{1}{c}{ Variable } & $\begin{array}{c}\text { FEV1 } \leq \mathbf{5 0} \\
(\mathbf{n}=\mathbf{1 4 9})\end{array}$ & $\begin{array}{c}\text { FEV1 } \geq \mathbf{5 1} \\
(\mathbf{n}=\mathbf{1 4 9})\end{array}$ & $\begin{array}{c}\boldsymbol{P} \\
\text { value }\end{array}$ \\
\hline Spinal drainage & $121(81.2)$ & $127(85.2)$ & .352 \\
Intercostal reimplantation & $49(32.9)$ & $67(45.0)$ & .032 \\
Renal/visceral perfusion & $24(16.1)$ & $37(24.8)$ & .012 \\
Partial bypass & $18(12.1)$ & $39(26.2)$ & .002 \\
Partial bypass time & & & \\
$\quad$ Median (Q1-Q3) & $26.5(21.5-31.3)$ & $25.0(21.0-27.0)$ & \\
$\quad$ Mean (SD) & $26.7 \pm 11.6$ & $27.9 \pm 10.6$ & .393 \\
Circulatory arrest & $8(5.4)$ & $16(10.7)$ & .089 \\
Circulatory arrest time & & & \\
$\quad$ Median (Q1-Q3) & $32.5(23.5-42.8)$ & $32.0(25.5-41.8)$ & \\
$\quad$ Mean (SD) & $33.0 \pm 10.5$ & $33.1 \pm 9.2$ & .273 \\
Clamp and sew & $123(82.6)$ & $94(63.1)$ & $<.001$ \\
Crossclamp time & & & \\
$\quad$ Mean (SD) & $31.0(24.0-37.0)$ & $28.0(24.0-38.3)$ \\
$\quad$ Mean (SD) & $30.4 \pm 11.5$ & $30.7 \pm 10.4$ & .214 \\
\hline
\end{tabular}

Data presented as $\mathrm{n}(\%)$, unless otherwise noted. FEVI, Forced expiratory volume in 1 second; $S D$, standard deviation. 
TABLE 4. In-hospital results in the propensity-matched population

\begin{tabular}{lccc}
\hline & \multicolumn{3}{c}{ Subgroups } \\
\cline { 2 - 4 } \multicolumn{1}{c}{ Variable } & $\begin{array}{c}\text { FEV1 } \leq \mathbf{5 0} \\
(\mathbf{n}=\mathbf{1 4 9})\end{array}$ & $\begin{array}{c}\text { FEV1 } \geq \mathbf{5 1} \\
(\mathbf{n}=\mathbf{1 4 9})\end{array}$ & $\begin{array}{c}\boldsymbol{P} \\
\text { value }\end{array}$ \\
\hline Operative death & $17(11.4)$ & $9(6.0)$ & .101 \\
Postoperative complications & & & \\
$\quad$ Major adverse events & $49(33.1)$ & $29(19.5)$ & .008 \\
Myocardial infarction & $2(1.4)$ & $1(0.7)$ & .558 \\
Stroke & $0(0.0)$ & $1(0.7)$ & .549 \\
Spinal complications & & & \\
$\quad$ Paraparesis & $6(4.1)$ & $1(0.7)$ & \\
$\quad$ Paraplegia & $1(0.7)$ & $0(0.0)$ & .163 \\
$\quad$ Delayed paraplegia & $2(1.4)$ & $1(0.7)$ & \\
New need for dialysis & $16(10.7)$ & $8(5.4)$ & .089 \\
Need for tracheostomy & $24(16.1)$ & $15(10.1)$ & .122 \\
Left recurrent nerve lesion & $8(5.4)$ & $8(5.4)$ & NS \\
Reoperation for bleeding & $6(4.0)$ & $3(2.0)$ & .310 \\
\hline
\end{tabular}

Data presented as $\mathrm{n}(\%)$, unless otherwise noted. $F E V I$, Forced expiratory volume in 1 second; $S D$, standard deviation.

difference in the incidence of major neurologic or cardiac complications. These same parameters were examined in matched populations (Table 4). Although the risk for an MAE was greater in those with low FEV1 $(33.1 \%$ vs $19.5 \%, P<.008)$, there was no substantial increase in operative mortality or individual postoperative complication in patients with reduced pulmonary function.

\section{Influence of Aneurysm Extent, Etiology, and Surgical Technique on Mortality}

The data outlining the effect of aneurysm extent, etiology, and technique on mortality are displayed in Table 5. Operative mortality was greatest with extent II aneurysms in both the overall and low FEV1 population; however, there was no difference in risk between DTAs and TAAAs in the overall population or in the subgroups analyzed. The use of circulatory arrest significantly increased the risk, although there was no difference in survival whether one used a clamp-and-sew strategy versus partial bypass. Although the mortality was greater in the overall cohort when the underlying disease was a chronic dissection, there was no significant difference compared with an atherosclerotic aneurysm $(7.1 \%$ vs $4.4 \%$, $P<.15)$. A low FEV1 added significant mortality risk when repairing aneurysms of either etiology.

\section{Independent Risk Factors and Survival}

With logistic regression analysis, preoperative FEV1 $\leq 50 \%$ was associated with a $6.99 \times$ increase in the risk of MAEs (95\% confidence interval 1.663-29.411, $P=.008)$. The only other preoperative independent predictor of MAE was renal insufficiency (odds ratio [OR] 3.01, 95\% confidence interval 1.46-6.21, $P=.003$ ).

Survival in the unmatched population is shown in Figure E3. In the matched groups, postoperative survival was significantly worse for patients with FEV1 $\leq 50 \%$ (Figure 1). Cox regression analysis in the matched population revealed preoperative spinal cord dysfunction (hazard ratio 3.397, 0.990-11.660) and the need for postoperative dialysis (hazard ratio $2.224,1.166-4.245$ ) to be highly predictive of long-term mortality (Table 6). FEV1 $\leq 50 \%$ was not an independent predictor of long-term death.

\section{DISCUSSION}

With an aging population and an overall increase in the prevalence of COPD ${ }^{11}$ surgeons performing DTA/TAAA repair are evaluating greater numbers of patients with compromised pulmonary function. Examination of the Nationwide Inpatient Sample database revealed a $25 \%$ incidence of COPD in 20,568 patients undergoing DTA repair ${ }^{15}$; others have found greater numbers of patients with the combination of aortic disease and advanced lung dysfunction. Fowkes and colleagues ${ }^{22}$ found $55 \%$ of patients undergoing abdominal aneurysm repair to have COPD, whereas LeMaire and colleagues ${ }^{23}$ reported a $47 \%$ incidence of COPD in their patients undergoing open aortic arch repair. In this study, $40.8 \%$ of 711

TABLE 5. Operative mortality by type of aneurysm in different populations

\begin{tabular}{lcccc}
\hline Type of aneurysm & Overall population & FEV1 $\leq \mathbf{5 0} \%$ & FEV1 $\geq \mathbf{5 1} \%$ & Intergroup $\boldsymbol{P}$ values \\
\hline DTA & $13 / 225(5.8 \%)$ & $6 / 44(13.6 \%)$ & $7 / 181(3.9 \%)$ & .022 \\
TAAA overall & $27 / 486(5.6 \%)$ & $14 / 115(12.2 \%)$ & $13 / 371(3.5 \%)$ & $<.001$ \\
TAAA extent I & $9 / 246(3.7 \%)$ & $4 / 56(7.1 \%)$ & $5 / 190(2.6 \%)$ & .132 \\
TAAA extent II* & $13 / 98(13.3 \%)$ & $8 / 27(29.6 \%)$ & $5 / 71(7.0 \%)$ & .013 \\
TAAA extent III-IV & $5 / 142(3.5 \%)$ & $2 / 32(6.2 \%)$ & $3 / 110(2.7 \%)$ & .363 \\
Partial bypass & $7 / 188(3.7 \%)$ & $2 / 18(11.1 \%)$ & $5 / 170(2.9 \%)$ & .104 \\
Circulatory arrest $\dagger$ & $9 / 61(14.8 \%)$ & $3 / 9(33.3 \%)$ & $6 / 52(11.5 \%)$ & .167 \\
Clamp and sew & $24 / 462(5.2 \%)$ & $15 / 132(11.4 \%)$ & $9 / 330(2.7 \%)$ & $<.001$ \\
Chronic dissection & $17 / 240(7.1 \%)$ & $8 / 32(25 \%)$ & $9 / 208(4.3 \%)$ & .001 \\
Atherosclerosis & $16 / 362(4.4 \%)$ & $10 / 100(10 \%)$ & $6 / 262(2.3 \%)$ & .003 \\
\hline Allo $)$
\end{tabular}

All other $P$ values not significant, except: $* P=.001$ versus extent 1 and 0.004 versus extent $3-4 . \dagger P=.002$ versus partial bypass and 0.003 versus clamp and sew. $F E V I$, Forced expiratory volume in 1 second; DTA, descending thoracic aortic aneurysm; TAAA, thoracoabdominal aortic aneurysm. 


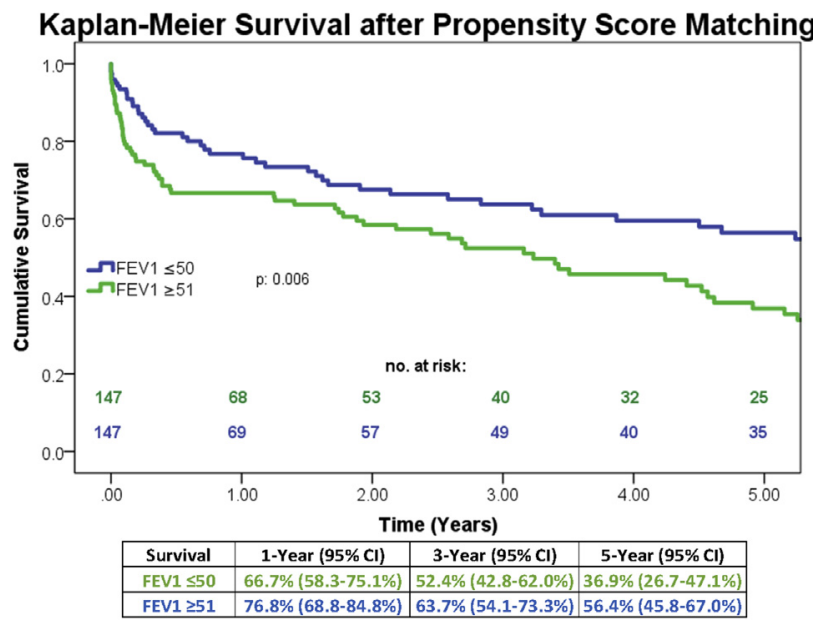

FIGURE 1. Kaplan-Meier estimate of survival for matched populations. FEV1, Forced expiratory volume in 1 second; $C I$, confidence interval.

patients undergoing open DTA/TAAA repair had COPD. Importantly, one-half of these patients had a significant reduction in their spirometry with an FEV $1 \leq 50 \%$. Given that the rates of thoracic aneurysm repair in the general population have increased from 2.2 to 10.6 per 1 million population during a 10-year period from 1998 to $2008,{ }^{15}$ the need to properly risk-stratify patients with COPD in need of aneurysm repair clearly is warranted. Thorough examination of the influence of COPD on open surgical outcomes seemed appropriate, especially so in an era of endovascular repair.

Although open DTA/TAAA repair remains a formidable surgical procedure, improvements in surgical technique and perioperative care have increased expectations dramatically for a successful outcome for those patients who may not be candidates for TEVAR. Surgical experience clearly matters. Our group and others have reported a substantial decline in operative mortality and the incidence of major postoperative complications when a team focused on performing open thoracic aneurysm repair is in place. ${ }^{24,25}$ Coselli and colleagues ${ }^{1}$ reported their experience with 3309 patients undergoing TAAA repair during a 30-year

TABLE 6. Cox regression analysis with predictors of long-term mortality in matched population

\begin{tabular}{llc}
\hline \multicolumn{1}{c}{ Predictor } & \multicolumn{1}{c}{ HR $(\mathbf{9 5} \% \mathbf{C I})$} & $\boldsymbol{P}$ value \\
\hline FEV1 $\leq 50$ & $1.283(0.838-1.962)$ & .251 \\
Female & $1.184(0.805-1.742)$ & .391 \\
COPD & $1.387(0.865-2.225)$ & .175 \\
Urgent/emergent procedure status & $1.240(0.802-1.916)$ & .333 \\
Preoperative renal failure & $1.373(0.931-2.023)$ & .109 \\
Preoperative paraplegia/paraparesis & $3.397(0.990-11.660)$ & .052 \\
New postoperative dialysis & $2.224(1.166-4.245)$ & .015 \\
\hline
\end{tabular}

$H R$, Hazard ratio; $C I$, confidence interval; $F E V I$, forced expiratory volume in 1 second; $C O P D$, chronic obstructive pulmonary disease. period. Despite having a high percentage of extent II aneurysms in their series, they reported an operative mortality of $7.5 \%$ with a composite adverse event rate of $14.4 \%$, including a low rate of permanent spinal cord injury. Estrera and colleagues ${ }^{3}$ also showed significant improvements in outcomes in another large cohort of patients when using advancements in end-organ protection such as partial bypass, spinal cord drainage, and intercostal reimplantation; however, with more widespread application of these adjuncts for end-organ protection, outcomes are becoming less dependent on how surgery is conducted and more on improving preoperative comorbidities and patient selection and, when possible, looking for less invasive alternatives when markers for a poor outcome are clearly present.

Compromised respiratory function remains a major risk factor for postoperative complications and death in many major surgical procedures. , $8,12-14,26,27$ Crestanello and colleagues $^{12}$ analyzed the Society of Thoracic Surgery Database for the influence of preoperative pulmonary function on more than 9000 patients undergoing aortic valve replacement. In those patients with an FEV1 $\leq 59 \%$, operative mortality was significantly greater (OR 2.88 ), as was the incidence of postoperative pulmonary complications (OR 2.33) and prolonged hospital stay (OR 2.73). They found a similar negative influence of low FEV1 on mortality and MAE in patients undergoing coronary bypass. The influence of preoperative respiratory function in patients undergoing more complex cardiovascular surgery was examined by Miyahara and colleagues ${ }^{13}$ in 269 patients after total arch replacement. They stratified patients according to the Global Initiative for Chronic Obstructive Disease scale. Those with moderate-to-severe symptomatic disease experienced a significant increase in respiratory complications such as pneumonia, prolonged ventilation, and the need for tracheostomy. Multivariable regression analysis showed a increase in in-hospital mortality for these patients (OR 10.18) in addition to a decline in overall survival (OR 2.6).

Open DTA/TAAA repair presents similar challenges that even extensive surgical experience cannot mitigate against. Coselli and colleagues ${ }^{1}$ reported increased mortality in those with pulmonary insufficiency. Although the presence of COPD was not associated with as great an increased mortality risk as significant renal dysfunction, it did double the mortality risk (OR 1.96) compared with those with more normal respiratory reserve. Although we were unable to demonstrate a significant increase in operative mortality or the need for tracheostomy in a PM matched population with an FEV1 $\leq 50 \%$, there was a significant increase in the incidence of MAEs $(33.1 \%$ vs $19.5 \%, P<.008)$. Similar to Coselli and colleagues, ${ }^{1}$ we did see a 4 -fold increase in operative mortality in an unmatched population with FEV $1 \leq 50 \%$ as well as a greater than 3 -fold increase 
in the need for tracheostomy and dialysis after surgery. The difference in 5-year survival in the matched population for those with severe COPD was also striking $(36.9 \%$ vs $56.4 \%, P=.006)$.

Given the potential influence of surgical technique, we wished to analyze 3 surgical strategies in more detail to see if one might be superior for those with severe respiratory compromise. Although many espouse the benefits of partial bypass in open DTA/TAAA repair, ${ }^{24,25}$ the avoidance of surgical lung manipulation and CPB may prove particularly beneficial in those with FEV1 $\leq 50 \%$. Asimakopoulos and colleagues ${ }^{28}$ showed a significant increase in lung injury with the use of CPB. CPB activated both complement and leukocytes as well as other inflammatory mediators, leading to a significant increase in respiratory failure after open heart surgery. The need for circulatory arrest and profound hypothermia may potentiate these inflammatory effects to an even greater degree. Zheng and colleagues ${ }^{29}$ demonstrated a significant increase in pulmonary injury mediated by an increase in interleukins 8 and 6 as well as the activation of nuclear factor kappa B in patients undergoing DHCA. Morimoto and colleagues ${ }^{30}$ also confirmed that the addition of pulmonary ischemia and microatelectasis during periods of circulatory arrest also had a negative influence on outcome for those undergoing total arch replacement. We also found the need for circulatory arrest in open DTA/TAAA repair to have a deleterious effect on outcome. Compared with lesscomplex strategies in either the overall cohort or those with reduced pulmonary function, circulatory arrest was associated with significant mortality. Although the more regular use of circulatory arrest for open DTA/TAAA repair can lead to excellent outcomes in experienced hands, ${ }^{31}$ we reserve this strategy for the limited number of patients who have anatomy unsuitable for proximal cross-clamping. In our experience, clamping proximal to the left subclavian artery is not associated with an increase in neurologic injury to either the brain or spinal cord. ${ }^{32}$ Expeditious aortic reconstruction with a simple clamp-and-sew method is reasonable for a majority of DTAs and extent I, III, and IV aneurysms, especially in those with extensive atherosclerosis where the use of partial bypass can contribute to catastrophic embolization. We advocate for the use of left heart bypass in a majority of extent II aneurysms as well as for chronic and acute dissections, especially in those with connective tissue disorders, where the complexity of repair is far greater and the burden of end-organ ischemia quite high.

Isolated DTAs constitute upwards of $40 \%$ of those undergoing thoracic aneurysm repair. ${ }^{33}$ Since the approval of stent-grafts for these aneurysms isolated to the chest, an increasing number of patients with DTAs have been treated with TEVAR. In patients with significant pulmonary dysfunction there may be some distinct advantages over open repair. Although the presence of COPD was not found to influence outcomes for either intact or ruptured DTAs in the Nationwide Inpatient Sample analysis of more than 20,000 patients, ${ }^{15}$ the GoreTAG Thoracic Endograft Trial demonstrated a substantial reduction in postoperative respiratory failure when comparing TEVAR with a historical group of controls undergoing open DTA repair $(4 \%$ vs $20 \%))^{34}$ In addition to the avoidance of altered respiratory mechanics associated with thoracotomy, the incidence of recurrent nerve injury is reduced markedly. This can lead to improved pulmonary toilet, a reduction in risk for aspiration, and a lower incidence of pneumonia. ${ }^{35}$ The incidence of recurrent nerve injury and tracheostomy in our overall cohort was $6 \%$ and $7.5 \%$, respectively; however, the need for tracheostomy was 3 times greater in those with FEV $1 \leq 50 \%(16.4 \%$ vs $4.9 \%, P<.001)$. For the $60 \%$ or so of patients with aneurysms extending below the diaphragm, open repair remains the gold standard therapy. For those with isolated DTAs, however, especially those with FEV $1 \leq 50 \%$, TEVAR should be explored as a primary repair strategy. Additional studies that compare TEVAR with open repair in patients with pulmonary dysfunction should lend additional clarity to the proper treatment of this high-risk cohort.

\section{Limitations}

This study is limited in its retrospective nature and for the lack of an adequately sized comparative group undergoing endovascular repair. The sample size, however, is reasonable to assess the influence of respiratory status on outcomes and the concordance of results achieved using advanced statistical techniques make a strong argument in favor of the reliability of these observations.

\section{CONCLUSIONS}

Preoperative FEV1 $\leq 50 \%$ predicted is a significant marker for respiratory dysfunction and is associated with a significantly greater incidence of operative mortality, need for tracheostomy, postoperative dialysis, and MAEs in an unmatched population undergoing open DTA/TAAA repair. When using propensity matching to adjust for differences in comorbidities and operative strategies, only the incidence of MAEs remains significantly greater in those with reduced pulmonary function. Patients with DTAs, especially in those with FEV1 $\leq 50 \%$, are excellent candidates for TEVAR. For those high-risk patients with severely COPD and TAAAs, the high incidence of postoperative respiratory failure warrants a discussion regarding the potential need for tracheostomy and possibility of reduced life-expectancy. A greater understanding of each institution's experience and outcomes with open repair may justify a search for alternative 
endovascular solutions for this extremely high-risk subset of patients.

\section{Conflict of Interest Statement}

Authors have nothing to disclose with regard to commercial support.

\section{References}

1. Coselli JS, LeMaire SA, Preventza O, de la Cruz KI, Cooley DA, Price MD, et al. Outcomes of 3309 thoracoabdominal aortic aneurysm repairs. J Thorac Cardiovasc Surg. 2016;151:1323-37.

2. Acher CW, Wynn MM, Mell MW, Tefera G, Hoch JR. A quantitative assessment of the impact of intercostal artery reimplantation on paralysis risk in thoracoabdominal aortic aneurysm repair. Ann Surg. 2008;248:529-40.

3. Estrera AL, Sandhu HK, Charlton-Ouw KM, Afifi RO, Azizzadeh A, Miller CC III, et al. A quarter century of organ protection in open thoracoabdominal repair. Ann Surg. 2015;262:660-8.

4. Lau C, Gaudino M, de Biasi AR, Munjal M, Girardi LN. Outcomes of open repair of mycotic descending thoracic and thoracoabdominal aortic aneurysms. Ann Thorac Surg. 2015;100:1712-7.

5. Afifi RO, Sandhu HK, Leake SS, Boutrous ML, Kumar V III, Azizzadeh A, et al. Outcomes of patients with acute type B (DeBakey III) aortic dissection: a 13-year, single-center experience. Circulation. 2015;132:748-54.

6. Gaudino M, Lau C, Munjal M, Girardi LN. Open repair of ruptured descending thoracic and thoracoabdominal aortic aneuyrsms. J Thorac Cardiovasc Surg. 2015; 150:814-21

7. Brunelli A, Kim AW, Berger KI, Addrizzo-Harris DJ. Physiologic evaluation of the patient with lung cancer being considered for resectional surgery: diagnosis and management of lung cancer, 3rd ed: American College of Chest Physicians evidence-based clinical practice guidelines. Chest. 2013;143(5 suppl):e166S-90S.

8. Brady AR, Fowkes FG, Greenhalgh RM, Powell JT, Ruckley CV, Thompson SG. Risk factors for postoperative death following elective surgical repair of abdominal aortic aneurysm: results from the UK Small Aneurysm Trial. On behalf of the UK Small Aneurysm Trial participants. Br J Surg. 2000;87: 742-9.

9. Girardi LN, Rabotnikov Y, Avgerinos DV. Preoperative percutaneous coronary intervention in patients undergoing open thoracoabdominal and descending thoracic aneurysm repair. J Thoracic Cardiovasc Surg. 2014;147:163-8.

10. Jarnagin WR, Gonen M, Fong Y, DeMatteo RP, Ben-Porat L, Little S, et al. Improvement in perioperative outcome after hepatic resection: analysis of 1,803 consecutive cases over the past decade. Ann Surg. 2002;236:397-406.

11. Ma J, Ward EM, Siegel RL, Jemal A. Temporal trends in mortality in the United States, 1969-2013. JAMA. 2015;314:1731-9.

12. Crestanello JA, Higgins RS, He X, Saha-Chaudhuri P, Englum BR, Brennan JM, et al. The association of chronic lung disease with early mortality and respiratory adverse events after aortic valve replacement. Ann Thorac Surg. 2014; 98:2068-77.

13. Miyahara S, Nakai H, Izawa N, Yamanaka K, Sakamoto T, Nomura Y, et al. Influences of chronic obstructive pulmonary disease on outcomes of total arch replacement. Ann Thorac Surg. 2015;99:72-8.

14. Saleh HZ, Mohan K, Shaw M, Al-Rawi O, Elsayed H, Walshaw M, et al. Impact of chronic obstructive pulmonary disease severity on surgical outcomes in patients undergoing non-emergent coronary artery bypass grafting. Eur J Cardiothorac Surg. 2012;42:108-13.

15. Kilic A, Shah AS, Black JH III, Whitman GJ, Yuh DD, Cameron DE, et al. Trends in repair of intact and ruptured descending thoracic aortic aneurysms in the United States: a population-based analysis. J Thorac Cardiovasc Surg. 2014; 147:1855-60.

16. Pape LA, Awais M, Woznicki EM, Suzuki T, Trimarchi S, Evangelista A, et al. Presentation, diagnosis, and outcomes of acute aortic dissection: 17-year trends from the international registry of acute aortic dissection. J Am Coll Cardiol. 2015;66:350-8.
17. Roselli EE, Abdel-Halim M, Johnston DR, Soltesz EG, Greenberg RK, Svensson LG, et al. Open aortic repair after prior thoracic endovascular aortic repair. Ann Thorac Surg. 2014;97:750-6.

18. Svensson LG, Hess KR, Coselli JS, Safi HJ, Crawford ES. A prospective study of respiratory failure after high-risk surgery on the thoracoabdominal aorta. J Vasc Surg. 1991;14:271-82.

19. Gowda S, Desai PB, Kulkarni SS, Hull VV, Math AA, Vernekar SN. Markers of renal function tests. North Am J Med Sci. 2010;2:170-3.

20. Cepeda MS, Boston R, Farrar JT, Strom BL. Comparison of logistic regression versus propensity score when the number of events is low and there are multiple confounders. Am J Epidemiol. 2003;158:280-7.

21. Ho DE, Imak K, King G, Stuart EA. Matching as non parametric preprocessing for reducing model dependence in parametric causal inference. Political Analysis. 2007;15:199-236.

22. Fowkes FG, Anandan CL, Lee AJ, Smith FB, Tzoulaki I, Rumley A, et al Reduced lung Function in patients with abdominal aortic aneurysm is associated with activation of inflammation and hemostasis, not smoking or cardiovascular disease. J Vasc Surg. 2006;43:474-80.

23. LeMaire SA, Price MD, Parenti JL, Johnson ML, Lay AD, Preventza O, et al Early outcomes after aortic arch replacement by using a Y-graft technique. Ann Thorac Surg. 2011;91:700-7.

24. Estrera AL, Miller CC III, Chen EP, Meada R, Torres RH, Porat EE, et al Descending Thoracic aortic aneurysm repair: 12-year experience using distal aortic perfusion and cerebrospinal fluid drainage. Ann Thorac Surg. 2005;80: 1290-6.

25. Tanaka H, Ogino H, Minatoya K, Matsui Y, Higami T, Okabayashi H, et al. Japanese Study of spinal cord protection in descending and thoracoabdominal aortic repair investigators. J Thorac Cardiovasc Surg. 2016; 151:122-8.

26. Khan MA, Hossain FS, Ahmed I, Muthukumar N, Mohsen A. Predictors of early mortality after hip fracture surgery. Int Orthop. 2013;37:2119-24.

27. Iba Y, Minatoya K, Matsuda H, Sasaki H, Tanaka H, Kobayashi J, et al Contemporary open aortic arch repair with selective cerebral perfusion in the era of endovascular aortic repair. J Thorac Cardiovasc Surg. 2013;145(3 suppl):S72-7.

28. Asimakopoulos G, Smith PL, Ratnatunga CP, Taylor KM. Lung injury and acute respiratory distress syndrome after cardiopulmonary bypass. Ann Thorac Surg. 1999;68:1107-15.

29. Zheng JH, Gao BT, Jiang ZM, Yu XQ, Xu ZW. Evaluation of early macrophage activation and NF-kappaB activity in pulmonary injury caused by deep hypothermia circulatory arrest: an experimental study. Pediatr Cardiol. 2010; 31:212-21.

30. Morimoto N, Morimoto K, Morimoto Y, Takahashi H, Asano M, Matsumori M et al. Sivelestat attenuates postoperative pulmonary dysfunction after total arch replacement under deep hypothermia. Eur J Cardiothorac Surg. 2008;34: 798-804.

31. Kouchoukos NT, Kulik A, Castner CF. Outcomes after thoracoabdominal aortic aneurysm repair using hypothermic circulatory arrest. J Thorac Cardiovasc Surg. 2013;145(3 suppl):S139-41.

32. Girardi LN, Krieger KH, Mack CA, Lee LY, Tortolani AJ, Isom OW. Does cross-clamping the arch increase the risk of descending thoracic and thoracoabdominal aneurysm repair? Ann Thorac Surg. 2005;79:133-7.

33. Isselbacher EM. Thoracic and abdominal aortic aneurysms. Circulation. 2005; 111:816-28.

34. Bavaria JE, Appoo JJ, Makaroun MS, Verter J, Yu ZF, Mitchell RS, Gore TAG Investigators. Endovascular stent grafting versus open surgical repair of descending thoracic aortic aneurysms in low-risk patients: a multicenter comparative trial. J Thorac Cardiovasc Surg. 2007;133:369-77.

35. Ohta N, Kuratani T, Hagihira S, Kazumi K, Kaneko M, Mori T. Vocal cord paralysis after aortic arch surgery: predictors and clinical outcome. J Vasc Surg. 2006;43:721-8.

Key Words: thoracoabdominal aortic aneurysm, descending thoracic aortic aneurysm, open repair, preoperative pulmonary function, aortic aneurysm 


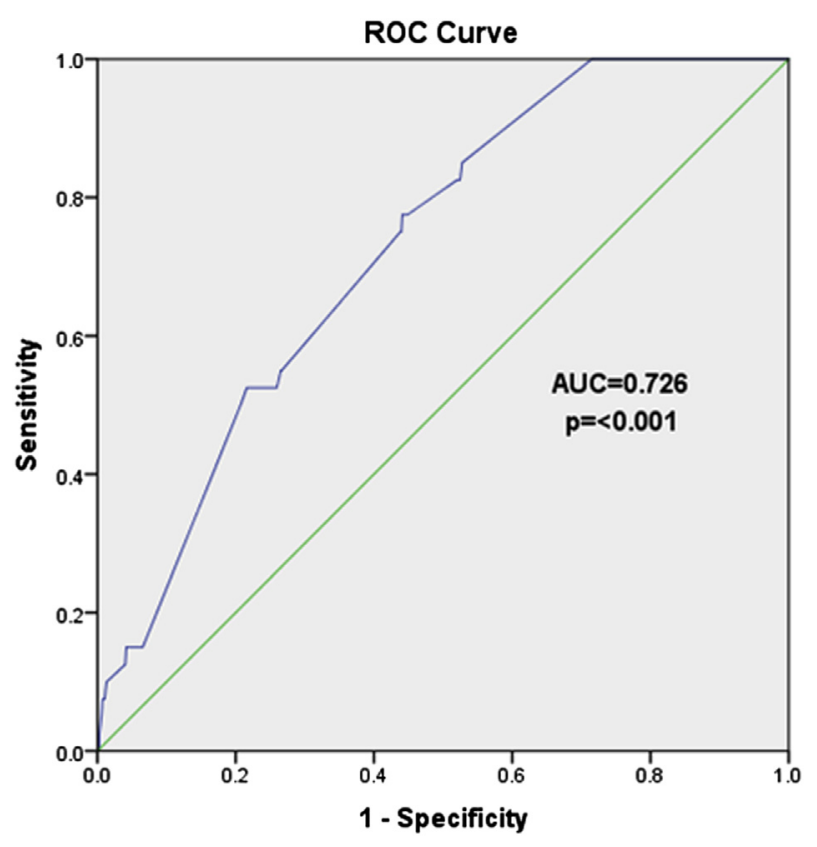

FIGURE E1. ROC curve illustrates sensitivity against specificity of forced expiratory volume in 1 second rate and death. AUC was found to be 0.726 , indicating a good model. ROC, Receiving operating characteristic; $A U C$, area under the curve.

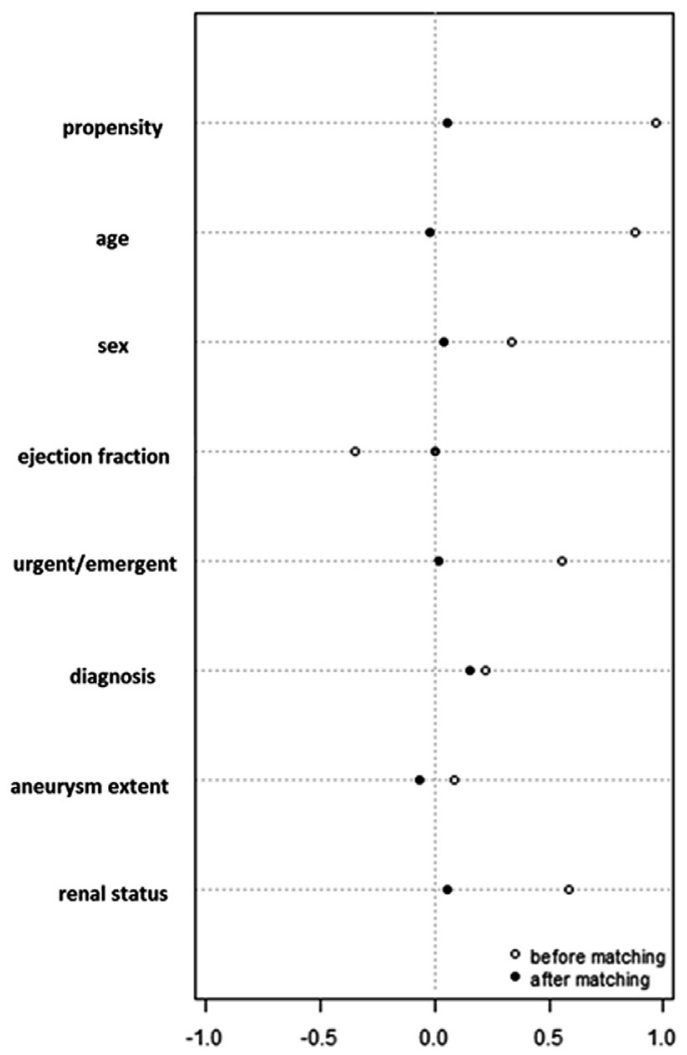

FIGURE E2. The dot plot displays the magnitude of the standardized differences before and after matching for each covariate. The standardized differences are much smaller once propensity analysis is conducted accounting for the listed covariates.

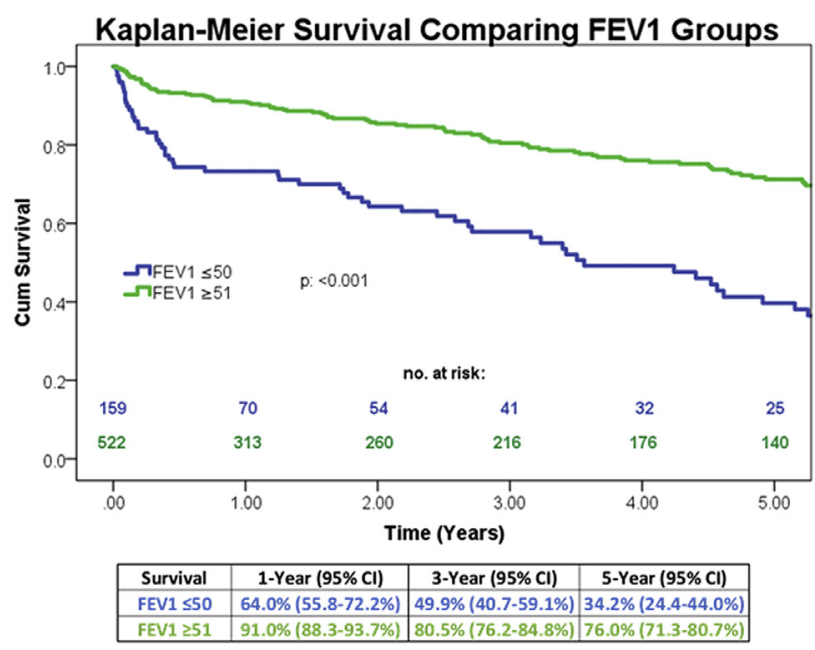

FIGURE E3. Kaplan-Meier estimate of survival for unmatched populations. FEV1, Forced expiratory volume in 1 second; $C I$, confidence interval. 
TABLE E1. Intraoperative data in the overall and unmatched population

\begin{tabular}{|c|c|c|c|c|}
\hline \multirow[b]{2}{*}{ Variable } & \multicolumn{4}{|c|}{ Subgroups } \\
\hline & Entire cohort $(n=711)$ & FEV1 $\leq 50(n=159)$ & $\operatorname{FEV} 1 \geq 51(\mathrm{n}=552)$ & $P$ value \\
\hline Spinal drainage & $598(84.1)$ & $130(81.8)$ & $468(84.8)$ & .358 \\
\hline Intercostal reimplantation & 287 (40.4) & $51(32.1)$ & $236(42.8)$ & .016 \\
\hline Renal/visceral perfusion & $150(21.1)$ & $26(16.4)$ & $124(22.5)$ & .096 \\
\hline Partial bypass & $188(26.4)$ & $18(11.3)$ & $170(30.8)$ & $<.001$ \\
\hline \multicolumn{5}{|l|}{ Partial bypass time } \\
\hline Median (Q1-Q3) & $27.0(23.0-31.0)$ & $26.5(21.5-31.3)$ & $27.0(23.0-30.0)$ & \\
\hline Mean \pm SD & $27.9 \pm 10.5$ & $26.7 \pm 11.6$ & $27.9 \pm 10.6$ & .646 \\
\hline \multicolumn{5}{|l|}{ Crossclamp time } \\
\hline Median (Q1-Q3) & $48.5(41.0-61.8)$ & $46.0(43.0-57.0)$ & $49.0(41.0-62.3)$ & \\
\hline Mean \pm SD & $52.3 \pm 16.2$ & $51.3 \pm 14.1$ & $52.4 \pm 16.5$ & .797 \\
\hline Circulatory arrest & $61(8.6)$ & $9(5.7)$ & $52(9.4)$ & .136 \\
\hline \multicolumn{5}{|l|}{ Circulatory arrest time } \\
\hline Median (Q1-Q3) & $33.5(27.0-43.0)$ & $39.0(24.0-44.5)$ & $33.0(26.5-43.5)$ & \\
\hline Mean \pm SD & $35.5 \pm 12.9$ & $34.9 \pm 11.3$ & $35.7 \pm 13.6$ & .864 \\
\hline Clamp and sew & $462(65.0)$ & $132(83.0)$ & $330(60.0)$ & $<.001$ \\
\hline \multicolumn{5}{|l|}{ Crossclamp time } \\
\hline Median (Q1-Q3) & $29.0(24.0-38.0)$ & $31.0(24.0-37.8)$ & $29.0(24.0-38.0)$ & \\
\hline Mean \pm SD & $30.1 \pm 11.5$ & $30.7 \pm 11.7$ & $30.0 \pm 11.5$ & .571 \\
\hline
\end{tabular}

TABLE E2. In-hospital results in the overall and unmatched population

\begin{tabular}{|c|c|c|c|c|}
\hline \multirow[b]{2}{*}{ Variable } & \multicolumn{4}{|c|}{ Subgroups } \\
\hline & Entire cohort $(n=711)$ & FEV1 $\leq 50(n=159)$ & FEV1 $\geq 51(n=552)$ & $P$ value \\
\hline Operative death & $40(5.6)$ & $20(12.6)$ & $20(3.6)$ & $<.001$ \\
\hline \multicolumn{5}{|l|}{ Postoperative complications } \\
\hline Major adverse events & $75(10.5)$ & $53(33.3)$ & $22(6.8)$ & $<.001$ \\
\hline Myocardial infarction & $4(0.6)$ & $2(1.3)$ & $2(0.4)$ & .181 \\
\hline Stroke & $5(0.7)$ & $0(0.0)$ & $5(0.9)$ & .228 \\
\hline \multicolumn{5}{|l|}{ Spinal complications } \\
\hline Paraparesis & $12(1.7)$ & $6(3.8)$ & $6(1.1)$ & .063 \\
\hline Paraplegia & $4(0.6)$ & $1(0.6)$ & $3(0.5)$ & \\
\hline Delayed paraplegia & $4(0.6)$ & $2(1.3)$ & $2(0.4)$ & \\
\hline New need for dialysis & $36(5.1)$ & $18(11.3)$ & $18(3.3)$ & $<.001$ \\
\hline Need for tracheostomy & $53(7.5)$ & $26(16.4)$ & $27(4.9)$ & $<.001$ \\
\hline Left recurrent nerve lesion & $43(6.0)$ & $8(5.0)$ & $35(6.3)$ & .542 \\
\hline Reoperation for bleeding & $16(2.3)$ & $6(3.8)$ & $10(1.8)$ & .142 \\
\hline
\end{tabular}

Data presented as n (\%), unless otherwise noted. FEVI, Forced expiratory volume in 1 second. 